\section{Escape from punishment by omission of responding'}

K. A. LATTAL and A. M. COOPER, University of Alabama, University, Ala. 35486

The elimination of punishment following pigeons failed to respond on the fixed-ratio operandum for predetermined time inter. vals. Both increases in the time interval required for escape from punishment and repeated exposure to each escape requirement interval resulted in reductions in the occurrence of escape behavior.

Escape requirements are usually defined by the occurrence of specified responses. For example, Azrin, Hake, Holz, \& Hutchinson (1965) delivered moderate punishment following each response on a fixed ratio (FR) schedule of positive reinforcement. Responses on a second operandum were maintained with both FR and fixed interval (FI) schedules when such behavior resulted in a temporary removal of the punishment contingency, allowing the $S$ to complete the FR requirement for positive reinforcement without the occurrence of punishment. This escape behavior was observed on FI escape schedules of up to $5 \mathrm{~min}$ in length for unspecified numbers of sessions.

Several investigators (Azrin, 1956; DeArmond, 1966; Hoffman \& Fleshler, 1965) have reported that organisms will passively avoid response-contingent electric shock by omitting responding in the presence of stimuli associated with such delivery of punishment. Hoffman \& Fleshler (1965) periodically superimposed a fixedduration warning stimulus upon a variable interval schedule of positive reinforcement. response during the last $2 \mathrm{~min}$ of the warning stimulus resulted in a cessation of responding which often continued until the warning stimulus, and associated punishment contingency, terminated. Although the $S s$ in each of these investigations avoided the delivery of punishment by omitting responding on the operandum, responding or failing to respond had no consequence on the removal of either the punishment the punishment. This experiment examined the occurrence of escape from a punishment contingency and its associated stimuli by the omission of responding on the operandum during a FR schedule of positive reinforcement. each response on a fixed-ratio schedule of positive reinforcement occurred whenever The delivery of punishment following each contingency or the stimuli associated with

\section{METHOD}

Two adult Silver King pigeons served as Ss and were maintained at $75 \%$ of their free-feeding weights. One $S$ was experimentally naive (161) and the second S (130) had a history of exposure to a conditionedsuppression paradigm.

A sound attenuated operant conditioning chamber of the type described by Ferster \& Skinner (1957) was used. The response key was transilluminated by a white triangle except as indicated below. Each daily session consisted of 50 presentations of a 2.5-sec access to Purina mixed grain for pigeons.

After training on a FR25 schedule, punishment was delivered following each response. The punishing stimulus was a 30 -msec presentation of 60-cycle ac delivered through a powerstat variable transformer and $10 \mathrm{~K}$ ohms to nichrome wire electrodes implanted around the pubis bones of the Ss. The intensity of the punisher through this resistance was $65 \mathrm{~V}$. This punishment resulted in FR behavior in accord with that reported by Azrin (1959), i.e., increased postreinforcement pause durations and resultant reductions in the overall rate of response.

The escape contingency was introduced after stable punished performance was obtained (a deviation of not greater than $\bar{X}$ $\pm 3 \%$ of the post reinforcement pause time during six consecutive sessions). Any complete omission of responding (pause) for a predetermined duration resulted in (a) a change in the stimulus projected on the response key from the white triangle to black and white diagonal stripes, and (b) a simultaneous removal of the punishment contingency, allowing completion of the remainder of the $F R$ requirement in the absence of punishment. Following reinforcement delivery, the triangle reappeared on the operandum, the punishment contingency was in effect, and the pause in responding was again required for the removal of the punishment contingency and associated stimulus change. Responses which occurred in the presence of the triangle restarted the time interval necessary for the removal of the punishment contingency. These responses also advanced the programming equipment the appropriate number of responses toward positive reinforcement delivery. Any pause of the required length, regardless of where it occurred during the FR requirement, resulted in the above changes. Since the escape requirement was defined only by the nonoccurrence of key-peck responses, the schedule is a conjoint FR25 + punishment (positive reinforcement) DRO (escape from punishment) reinforcement schedule (cf Catania, Deegan, \& Cook, 1966).

Initially the DRO escape schedule was gradually increased to $15 \mathrm{sec}$, an interval which exceeded both the mean and median postreinforcement pause observed during the stable FR25 + punishment schedule. Following the 15-sec schedule the DRO escape schedule was increased to $30 \mathrm{sec}$ and finally to $45 \mathrm{sec}$. This sequence of temporal escape schedules was repeated until the escape behavior dissipated to a low level at each. Each requirement remained in effect for approximately 14 sessions $(\bar{X}=14.2$ ses-
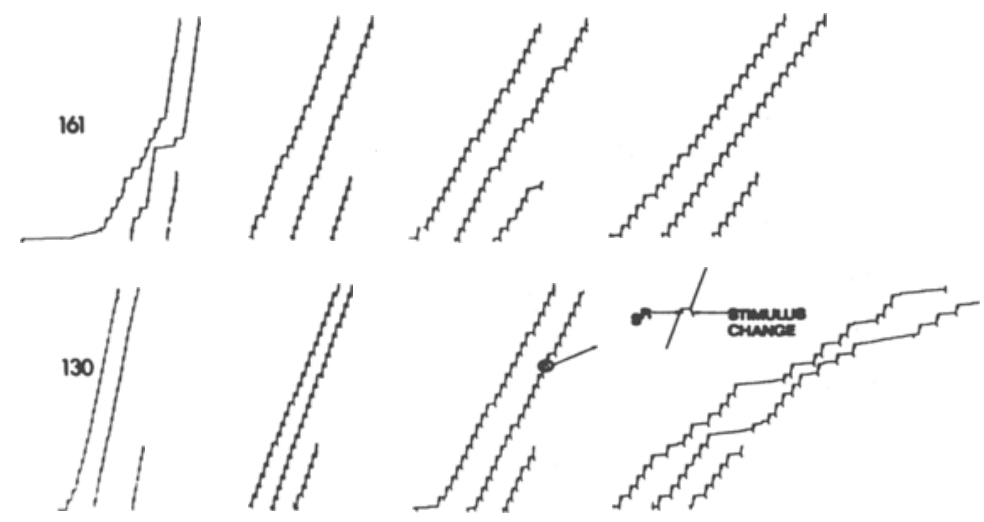

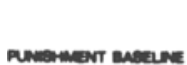

$30 \mathrm{sac}$.

$45 \sec$.
Fig. 1. Representative cumulative records of the behavior of both Ss during the first exposure to each of the DRO escape requirements. The inset describes the occurrence of reinforcement ( $S^{R}$, indicated by a short pip of the response pen) and the elimination of the punishment contingency and associated stimulus change (indicated by a longer pip of the response pen). 
sions; range $=9-35$ sessions). Following the first sequence of escape requirements, the FR25 + punishment schedule was reinstated prior to the next exposure to the conjoint schedule. On subsequent replications this schedule was not reinstated because of the large decrements in escape behavior at the longer DRO intervals.

\section{RESULTS AND DISCUSSION}

Greater than $98 \%$ of the total responses per session were emitted in the absence of punishment during the first exposure to DRO 15- and 30-sec escape requirements by Bird 130 and at all three escape requirements during the first and second exposures by Bird 161. The latency between the occurrence of the stimulus change signaling the omission of punishment and the onset of the FR run was typically less than $1 \mathrm{sec}$. During this first exposure to the conjoint schedule many of the escape requirements were met without the occurrence of a punished response, i.e., during the postreinforcement pause (see Fig. 1). However, responses in the presence of the stimulus associated with punishment sometimes occurred, especially at the longer DRO requirements. Such behavior is especially prevalent in the cumulative record of Bird 130 (Fig. 1) during the 45-sec escape requirement. The sample cumulative records also illustrate the overall increase in the amount of time spent pausing during the conjoint schedule relative to the amount of pausing which occurred without this escape contingency in effect (i.e., during the punishment baseline condition). With successive replications, the DRO escape requirement was met less frequently. The per cent of unpunished responses decreased first at the longer escape intervals and later even at the DRO 15-sec escape requirement (Fig. 2).

The results of the initial exposures to the DRO escape requirements are consistent with the findings of Azrin et al (1965) that organisms will engage in behavior which eliminates a punishment contingency. These data also extend the earlier observations of Azrin (1956), DeArmond (1966), and Hoffman \& Fleshler (1965) to a situation in which the escape from punishment is actually contingent upon a "passive" response with respect to the food-producing operandum.

There is a diminution of the escape behavior both as the escape requirement is increased and as the organism develops a

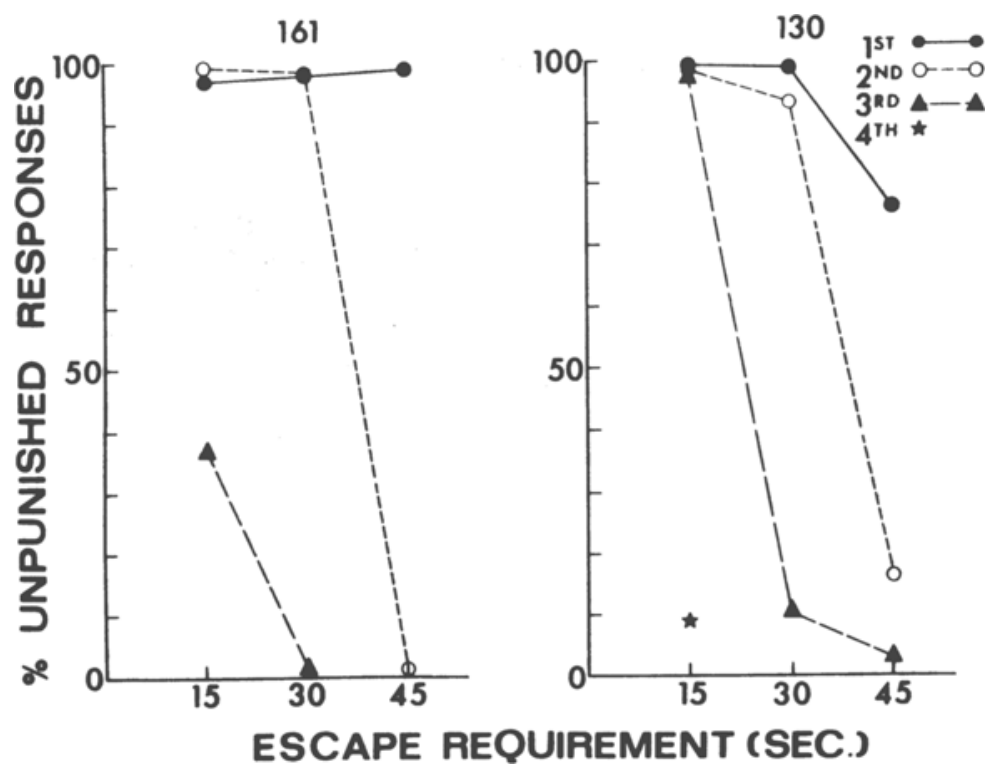

Fig. 2. The per cent of unpunished responses at each escape requirement during successive exposures (see legend) to the DRO escape requirements. Each point is the mean of the last five sessions during the conditions indicated.

history of exposure to punishment through repeated exposure to the conjoint schedule. Azrin et al (1965) report a somewhat similar effect to the former observation during a FI escape from punishment schedule. In the present experiment, two processes may be operating to produce the decrements in escape behavior. The completion of a temporal escape requirement in this situation necessarily decreases the frequency of positive reinforcement (reinforcements per unit time) as the $S$ eliminates responses on the operandum. Further, with repeated exposure to punishment, recovery from its effects is to be expected during a FR at this intensity of the punishing stimulus (Azrin, 1959). With a lessening effect of the punishment upon the behavior, there is an increase in the overall rate of response and, as a result, an increase in the frequency of positive reinforcement on the FR schedule. This increase in the frequency of positive reinforcement might further increase the rate (cf. Reynolds, 1961) which would then result in further decrements in the DRO escape behavior.

\section{REFERENCES}

AZRIN, N. H. Some effects of two intermittent schedules of immediate and non-immediate punishment. Joumal of Psychology, 1956, 42, 3-21.
AZRIN, N. H. Punishment and recovery during fixed ratio performance. Journal of the Experimental Analysis of Behavior, 1959, 2, 301-305.

AZRIN, N. H., HAKE, D. F., HOLZ, W. C., \& HUTCHINSON, R. R. Motivational aspects of escape from punishment. Journal of the Experimental Analysis of Behavior, 1965, 8, 31-44.

CATANIA, A. C., DEEGAN, J. F., \& COOK, L. Concurrent fixed-ratio and avoidance responding in the squirrel monkey. Joumal of the Experimental Analysis of Behavior, 1966, 8, 227-231.

DeARMOND, D. Multiple punishment schedule. Journal of the Experimental Analysis of Behavior, 1966, 9, 327-334.

FERSTER, C. B., \& SKINNER, B. F. Schedules of 1957.

HOFFMAN, H. S., \& FLESHLER, M. Stimulus aspects of aversive controls: The effects of response contingent shock. Journal of the Experimental Analysis of Behavior, 1965, 8, 89-96.

REY NOLDS, G. S. Relativity of response rate and reinforcement frequency in a multiple schedule. Journal of the Experimental Analysis of Behavior, 1961, 4, 179-184.

NOTE

1. We thank Dr. Paul Weisberg for his valuable comments. Reprints may be obtained from A.M. Cooper. reinforcement. New York: Appleton Century, 